\title{
Your teeth
} you are in control'

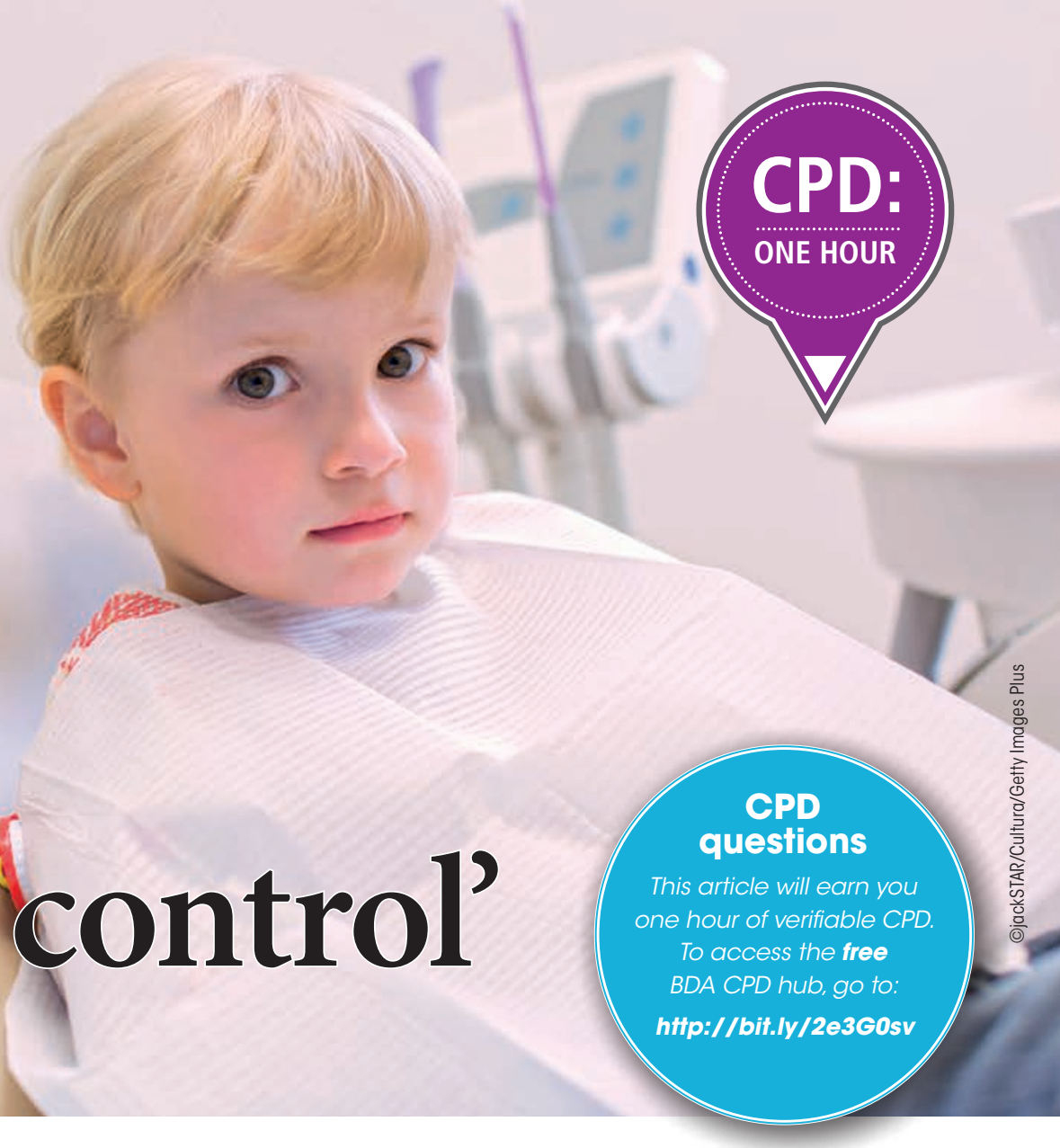

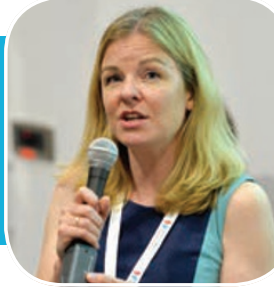

Dr Zoe

Marshman'

writes

about the

new self-help Cognitive

Behavioural Therapy

(CBT) guide to reduce

dental anxiety in children.

'Reader in Dental Public Health, School

of Clinical Dentistry, University of Sheffield
Background to dental anxiety

Dental anxiety is common, affects people of all ages and tends to develop in childhood and adolescence. ${ }^{1,2}$ The Child Dental Health survey in 2013 found $14 \%$ of 12 -year-olds and $10 \%$ of 15 -year-olds were classified as having extreme dental anxiety. ${ }^{3}$

\section{Impact on children}

Children with high levels of dental anxiety have more decayed and extracted teeth with unmet need for dental care. ${ }^{4} \mathrm{Up}$ to one in five young people report not visiting the dentist regularly because of fear ${ }^{5}$ or not completing dental treatment. ${ }^{6}$ Children themselves when describing their experiences of dental anxiety report making negative predictions about what could happen (eg suffering pain or harm, clinical error, being powerless); reliving traumatic dental experiences; avoiding dental care by using deceptive or negotiation strategies; experiencing negative affective states (eg fear, anxiety, anger, shame, embarrassment), and physical symptoms of sweating and shaking. ${ }^{7}$

\section{Impact on parents}

Child dental anxiety also has an impact on parents. Hallberg and colleagues found that parents experienced difficulties trying to persuade their dentally-anxious children to go to their appointments and lacked strategies to handle their child's level of fear and effectively manage the situation. ${ }^{8}$

Impact on dental services

Dental anxiety in young people also has a significant impact on dental services. Providing dental treatment for anxious patients is time consuming, demanding and a cause of occupational stress. ${ }^{9}$ Patients typically end up being referred to paediatric dentistry services, having to wait longer for dental treatment and at increased costs to the NHS. ${ }^{10}$

Traditionally, dental anxiety has been managed using pharmacological techniques including inhalational sedation and general anaesthetic (GA). However, such approaches only manage rather than reduce children's dental anxiety. ${ }^{11}$ The cost per case for inhalational sedation or GA for dental treatment has been estimated at $£ 273$ and $£ 720$ respectively. ${ }^{12}$ Indeed, dental anxiety remains unchanged in those children who receive dental treatment under general anaesthetic ${ }^{13}$ with anxious children becoming adults with a long-term reliance on expensive pharmacological techniques.

\section{Ways to reduce anxiety}

Over recent years it has been recognised that greater effort should be directed towards behaviour management and psychological interventions which can reduce patients' 
anxiety long-term. ${ }^{14,15}$ Cognitive Behavioural Therapy (CBT) is a goal-orientated talking therapy which aims to help people manage their problems by changing how they think and behave in relation to their problems. CBT incorporates a variety of different cognitive and behavioural strategies which aim to help the patient modify the unhelpful behaviours or thoughts maintaining their anxiety. ${ }^{16} \mathrm{~A}$ review of meta-analyses revealed that $\mathrm{CBT}$ is highly effective in treating a range of general anxiety disorders in both children and adults. ${ }^{17}$

\section{Ways to reduce dental anxiety in children}

CBT interventions have shown promising results in reducing dental anxiety in adults in terms of effectiveness, acceptability and benefits enduring over time. ${ }^{18-21}$ While strategies such as providing information, 'tellshow-do', stop signalling, graded exposure, systematic desensitisation and modelling interventions are regularly employed by dentists and dental care professionals with children there is a paucity of research about the effectiveness of CBT for reducing children's dental anxiety. ${ }^{22}$

\section{'Your teeth you are in control'}

Recently, a self-help guide and accompanying resources, based on the principles of CBT, has been developed for use with children aged 9-16 years and delivered by dental practitioners and dental care professionals. ${ }^{23}$ Experts in paediatric dentistry, child clinical psychology, health psychology, dental public health and CBT led the process with children, parents, dental team members and Patient and Public Involvement representatives all involved. A person-centred approach was used based on the Five Areas ${ }^{\mathrm{TM}}$ model of $\mathrm{CBT}^{24}$

The guide 'Your teeth you are in control' includes information on the dental team and basic procedures; describes tools children can use to help them feel less anxious; contains activities children can complete to feel more in control including a 'message to dentist' and a stop signal signed agreement; and prompts them to reflect on what went well about each visit. The step-by-step process of using the guide is described in Figure 1. The guide is suitable for children with mild to moderate dental anxiety who require a course of treatment but have no urgent dental treatment needs.

'Your teeth you are in control' was used with a sample of new patients who attended the community dental service in Derbyshire or the paediatric dentistry department of
Fig. 1 How to use the Cognitive Behavioural Therapy self-help resources with dentally anxious children (9-16 years)

\section{Prior to using the guide:}

- Register on website www.llttf.com/dental

- Visit the 'dental team' section of the site, view the training videos and read the dental team guide - it might be helpful for other members of the team to do this too.

- Think about how you are going to assess child dental anxiety: clinical impression or self-reported measure

- Obtain hard copy guides for patients or print flyers which signpost them to the online self-help guides. Available from the Sheffield School of Clinical Dentistry online shop.

- Download spare patient worksheets (eg 'Message to the dentist') and have these available on the clinic.

\section{Identify patients where self-help CBT is indicated:}

- Patient is assessed as having dental anxiety

- No urgent treatment needed

- Course of treatment required

- Child and family interested in self-help approach

\section{Guide is introduced by dental professional who will be providing the course of dental treatment:}

- Describe as 'self-help' guide, avoiding any descriptions of need to do work or books!

- Explain paper guide and online versions available for child and parent

- Highlight was developed with teenagers to increase credibility

- Ask child to have a look through and complete 'Message to the dentist' for their next visit
At the start of each visit:
- Read or review 'Message to the dentist'
- Recognise their past achievements
- Discuss worry/pain score
- Agree tools and stop signal

\section{At the end of each visit:}

- Provide specific praise for what they have achieved in the visit

- Complete post-treatment worry/pain score (remind of successes)

- Plan for next appointment (let them know what the procedures will involve and signpost them to the guide as appropriate)

Charles Clifford Dental Hospital in Sheffield. Overall, 56 children were consented to take part in the study with 48 children completing three treatment visits and questionnaires before and after treatment. Of these 48 children, 33 were female (69\%), 25 lived in deprived areas (52\%) and 36 were referred for the management of dental caries (75\%). There was a statistically significant reduction in child self-reported dental anxiety and improvements in quality of life with nearly two-thirds (60\%) indicating they felt 'a lot

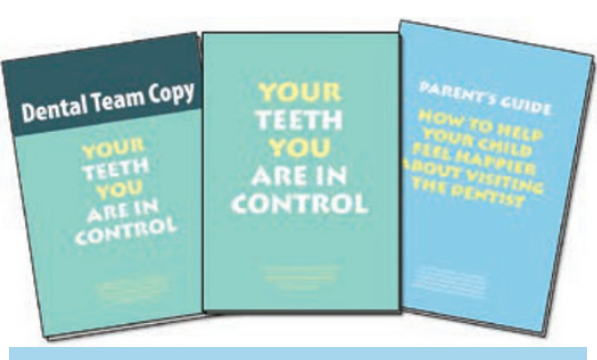

Fig. 2 Self-help CBT guide for the reduction of dental anxiety in children with accompanying resources for parents and dental professionals 
less worried' about going to the dentist since using the guide. The guide was found to be acceptable to children, parents and dental professionals. Further research was recommended to evaluate this self-help guide in a randomised controlled trial ${ }^{23}$ and its further use in both secondary and primary dental care is encouraged.

'Your teeth you are in control' is available as a paper guide http://tinyurl.com/hc998fl or online at www.llttf.com/dental. There are also accompanying resources for parents (Fig. 2) and online training for dental professionals.

\section{Summary}

- Child dental anxiety is common and has significant impacts on children, parents and dental professionals

- Traditional pharmacological approaches only manage, rather than reduce dental anxiety

- Psychological interventions such as CBT have been found to be effective at reducing dental anxiety in adults

- The use of a new guide 'Your teeth you are in control' based on the principles of CBT reduced dental anxiety and improved the quality of life of children who used it in paediatric dentistry clinics.

For more information contact Z.Marshman@ sheffield.ac.uk.
Carrasco P, Rogerleroi V, Hennequin M. Factors affecting dental fear in French children aged 5-12 years. Int J Paediatr Dent 2010; 20: 366-73.

5. Taani D Q. Dental attendance and anxiety among public and private school children in Jordan. Int Dent J 2002; 52: 25-29.

6. McGoldrick P, Levitt J, de Jongh A, Mason A, Evans D. Dental anxiety: Referrals to a secondary care dental clinic for anxious adult patients: implications for treatment. Br Dent J 2001; 191: 686-688.

7. Morgan A G, Rodd H D, Porritt J M et al. Children's experiences of dental anxiety. Int J Paediatr Dent 2016; DOI: 10.1111/ ipd.12238.

8. Hallberg U, Camling E, Zickert I, Robertson A, Berggren U L F. Dental appointment no-shows: why do some parents fail to take their children to the dentist? Int J Paediatr Dent 2008; 18: 27 34.

9. Moore R, Brodsgaard I. Dentists' perceived stress and its relation to perceptions about anxious patients. Community Dent Oral Epidemiol 2001; 29: 73-80.

10. Harris R V, Pender S M, Merry A, Leo A. Unravelling referral paths relating to the dental care of children: a Study in Liverpool. Prim Dent Care 2008; 15: 45-52.

11. Koroluk L D. Dental anxiety in adolescents with a history of childhood dental

\section{'THERE WAS A STATISTICALLY SIGNIFICANT}

\section{REDUCTION IN CHILD SELF-REPORTED}

\section{DENTAL ANXIETY AND}

\section{IMPROVEMENTS IN QUALITY OF LIFE'}

1. Locker D, Liddell A, Dempster L, Shapiro D. Age of onset of dental anxiety. J Dent Res 1999; 78: 790-796.

2. Locker D, Thomson W M, Poulton R. Onset of and patterns of change in dental anxiety in adolescence and early adulthood: a birth cohort study. Community Dent Health 2001; 18: 99-104.

3. Health and Social Care Information Centre. Children's Dental Health Survey 2013: Attitudes, Behaviours and Children's Dental Health: England, Wales and Northern Ireland. London: Health and Social Care Information Centre, 2015.

4. Nicolas E, Bessadet M, Collado V, sedation. ASDC J Dent Child 1999; 67: 200-205, 161.

12.NICE. Sedation in children and young people. Costing report: Implementing NICE guidance. London: 2010.

13. Arch L M, Humphris G M, Lee G T R. Children choosing between general anaesthesia or inhalation sedation for dental extractions: the effect on dental anxiety. Int J Paediatr Dent 2001; 11: 41-48.

14. Bankole O O, Aderinokun G A, Denloye O O, Jeboda S O. Maternal and child's anxiety--effect on child's behaviour at dental appointments and treatments. Afr J Med Med Sci 2002; 31: 349-52.
15. Levitt J, McGoldrick P, Evans D. The management of severe dental phobia in an adolescent boy: a case report. Int J Paediatr Dent 2000; 10: 348-353.

16. Williams C, Garland A. A cognitivebehavioural therapy assessment model for use in everyday clinical practice. Advances in Psychiatric Treatment 2002; 8: 172-179.

17. Butler A C, Chapman J E, Forman E M, Beck A T. The empirical status of cognitive-behavioral therapy: A review of meta-analyses. Clin Psychol Rev 2006; 26: 17-31.

18. Gordon D, Heimberg R G, Tellez M, Ismail A I. A critical review of approaches to the treatment of dental anxiety in adults. $J$ Anxiety Disord 2013; 27: 365-378.

19. Spindler H, Staugaard SR, Nicolaisen C, Poulsen R. A randomized controlled trial of the effect of a brief cognitive-behavioral intervention on dental fear. J Public Health Dent 2015; 75: 64-73.

20.Boman U W, Carlsson V, Westin M, Hakeberg M. Psychological treatment of dental anxiety among adults: a systematic review. Eur J Oral Sci 2013; 121: 225-234.

21. Willumsen T, Vassend O. Effects of cognitive therapy, applied relaxation and nitrous oxide sedation. A five-year followup study of patients treated for dental fear. Acta Odontol Scand 2003; 61: 93-99.

22. Porritt J, Marshman Z, Rodd H D. Understanding children's dental anxiety and psychological approaches to its reduction. Int J Paediatr Dent 2012; 22: 397-405.

23. Porritt J M, Rodd H D, Morgan A G et al. Development and testing of a cognitive behavioral therapy resource for children's dental anxiety. JDR Clinical \& Translational Res 2016; DOI:10.1177/2380084416673798.

24. Williams C. Overcoming anxiety, stress and panic: a five areas approach. CRC Press, 2012.

\section{CPD questions}

This article has four CPD questions attached to it which will earn you one hour of verifiable CPD.

To access the free BDA CPD hub, go to http://bit.ly/2e3G0sv. There are ten free hours of CPD available each year!

bdjteam201710 